\title{
Sobre el estilo de Unamuno
}

\section{John Lionel O’Kuinghttons Rodríguez}

\section{RESUMEN}

Este ensayo tiene como objetivo reflexionar sobre el estilo de Miguel de Unamuno, dar algunas características de su prosa e identificar ciertas dificultades con que el traductor de su libro Del sentimiento trágico de la vida puede depararse. Para que dicha reflexión no quede disociada del contenido del libro reviso sucintamente el meollo de las atenciones que atarearon al escritor español en torno al tema de la trascendencia humana.

En un momento de su libro Sables y Utopías (2009), Mario Vargas Llosa relaciona la conocida efusión verbal a que tiende la literatura española con la ausencia de un sistema filosófico propio en nuestro idioma. Según su diagnóstico, el castellano es un edificio adjetival prolijo, abundante, pirotécnico, emocionalmente expresivo pero conceptualmente inope. En esta preliminar Llosa no advierte una inconveniencia anterior: el entendimiento de las lenguas como entidades autónomas. Es de perogrullo oír que una lengua no admite cierta lateralidades en sus artículos o que limita y hasta impide la conjugación de tales y cuales verbos. Estas visitadas aserciones, cuya vocería puede deberse a una mera comodidad dialógica, parecen ignorar que no existe idioma autócrata, que toda lengua se funda en los hablantes que la ofician. Son estos y no las minuciosas gramáticas quienes decidirán, por ejemplo, la extensión del verbo abolir o absolverán al verbo haber de su pretendida impersonalidad. A Llosa no lo atarea esta discusión, antes quiere mostrar que el idioma español ha sido históricamente trabajado más como cuerpo de expresión que como laboratorio especulativo.

Pensar en filosofía española, añade, es invocar a Ortega y Gasset, quien, más que pensador fue un literato. Sin aludirlo directamente, el otro autor que hospeda esta sucinta nómina es don Miguel de Unamuno. Sabemos que su obra escrita, además de profusa, convocó a la mayor parte de los géneros que concita la literatura. Fue un polemista activo, un observador de la realidad española tan controvertido que se granjeó la enemistad de los autoritarismos. Por esta ojeriza ejerció de modo oscilante la rectoría de la universidad de 
Salamanca. Como Swedenborg, fue lector solícito de la Biblia, conoció bien el racionalismo, del que acabó descreyendo, y el positivismo. Aprendió el danés para amistar sin intermediarios con el existencialismo de Kierkegaard. Abogaba por una filosofía que se ocupara del hombre de carne y hueso, el hombre que nace, sufre y muere -sobre todo muere-, el que come y bebe y juega y duerme y piensa y quiere, el hombre que se ve y a quien se oye, el hermano, el verdadero hermano. Nunca admitió una filosofía que se restringiera a las meras limitaciones documentales; una filosofía despojada de pasión, pensaba, solo encuadra en esta categoría por la mera atribución del nombre.

Las cuestiones teológicas superaron poderosamente la embriaguez de los ritos sociales del catolicismo. Unamuno sostuvo que en el ser católico la escatología domina a la ética. Esta calidad es visible, por ejemplo, en el ascetismo monástico, cuya moral prescribe la salvación del alma individual antes que la edificación social. Un beato recluso en su habitación, anhelante de la reflexión y el ascenso celestial se atiene únicamente a sí mismo, a su trascendencia, no a la de sus prójimos. Ya que la obsesión por la inmortalidad incumbe a legos y beatos, Unamuno negó la eventualidad de que alguien no haya pensado siquiera una vez en su propia trascendencia.

En Del sentimiento trágico de la vida (1901) expone que la fe en una deidad es la trabajada esperanza de que esta vida material no se prolongue en una vida ulterior. Este difuso deseo desautoriza la falta de evidencias. La razón desmiente la prosecución extra corporal, pero es incapaz de refutar su inexistencia. Mientras la razón recusa, el sentimiento aprueba. Esta colisión irresoluble es la que genera el sentimiento trágico de la vida. No es la razón sino la angustia vital lo que nos induce a forjar a dios. Quien afirma creer en dios pero no le teme profesa la creencia en la idea de dios y en quienes le enseñaron que existe, pero no en dios mismo.

La fe no es creer lo que no vimos sino crear lo que no vemos. El creyente es quien fragua la creencia, sostiene Unamuno, secundado por Daniel Denett, que quizás lo leyó. Esta ansia se evidencia principalmente en el edificio de la religión, que no es único. El hombre que amoneda su nombre en un libro, en una tela, en la partitura de un concierto, en el apellido de sus hijos busca, aun sin advertirlo, la anulación del inmanentismo. Viene a cuento recordar que para Bertrand Russell (2008) los argumentos que suscitan la creencia en otra vida no son racionales sino estrictamente emocionales. 
Unamuno enseña que no es la convicción en otra vida lo que nos torna buenos, sino que, por ser buenos somos capaces de concebir un allende. El hombre vil no puede concebirlo, quizás porque al imaginarlo se arriesga a la eventualidad de una penalización ilimitada. Niega además que podamos anhelar la trascendencia sin formarnos una representación de ese último estadio. Quien desea la continuidad añora una reproducción de las condiciones y materias que conoce. Swedenborg (2008) entendió que ese orbe replica fielmente la vía pasajera, salvo en que las cosas, las sensaciones, los colores se tornan más esplendorosos. Al morir, una persona no percibe su nuevo estado, pero paulatinamente comienza a observar que sus sentidos acogen sensaciones inconcebiblemente más intensas que antes.

Lo que en definitiva deseamos es dilatar esta existencia, perpetuar su materia, sus diálogos, su comercio, pero desvestida de sus padecimientos, como una propagación mejorada de la felicidad corporal. La imagen celeste legada por los beatos es la de un recinto incólume, luminoso, pero regido irremediablemente por el tedio. Es la imaginación que usó Dante al componer los territorios de ultra tumba. El cielo dantesco es un espacio poblado de luces, himnos y de una placidez tan ilimitada que la curiosidad queda abolida. No menos relevante es el interés que ha concitado desde siempre la ideación física del Infierno. Su estructura ministerial, sus fuegos, sus laceraciones y castigos nunca le fueron indiferentes a la fe, que publica el miedo, ni al arte, que compagina su espantosa belleza. Por lo demás, el infierno de Dante es habitación de personajes infinitamente más seductores que los impertérritos residentes de su antípoda.

Tras los doce laboriosos ensayos de Del sentimiento trágico de la vida Unamuno nos suministra la conclusión de que debemos creer en la otra vida no solo para soportar esta sino también para y darle sentido y finalidad.

Hasta aquí el examen medular de las ideas que atarean su libro. Ciertamente Del sentimiento trágico de la vida puede provocar tanto acuerdos como disensiones. Al menos en principio, un ensayista no debiera fijarse como objetivo dorsal la persuasión o la disuasión de su lector, sino el contumaz tejido de sus íntimas opiniones. Creo que la variabilidad de anuencia o desacuerdo no comparece en la evaluación del estilo de don Miguel de Unamuno. 
Vargas Llosa niega que los excesos retóricos típicos de la lengua española sean una impropiedad y congenia con la defensa argüida por el escritor vasco: la comunidad española se manifiesta mejor en la expresión florida y concreta antes que en la concisión abstracta. Unamuno aboga por la expresión más auténtica y desesperada porque el asunto que trabaja condice con la exaltación. Él mismo admite que su exposición arriesga la contradicción, pues el entrabe deviene de la imposibilidad de conciliar entre el anhelo de inmortalidad y la imparcialidad de razón.

Al dejar el examen del contenido y transitar al dominio de la forma admitamos dos criterios de entrada: a) que la prosa de Unamuno cumple con la efusión diagnosticada por Vargas Llosa; b) que los alambiques verbales de Del sentimiento trágico de la vida se convierten en un obstáculo para la tarea del traductor.

Harold Bloom (1994) sostiene que una de las cualidades que favorece la integración de un escritor al canon es su capacidad de contagio. Cervantes es el aura más poderosa que han debido arrostrar los artistas españoles. De alguna forma, la literatura ibérica ha buscado ser Miguel de Cervantes. De alguna forma, don Miguel de Unamuno fue Miguel de Cervantes $^{1}$, sin lograr eximirse de sus propias deficiencias. Unamuno, por ejemplo, no logra incoar un párrafo sin la mediación de copiosas frases intercaladas que no pocas veces entrampan la identificación de los sujetos. Las intromisiones son hospitalarias con neologismos como sobrenaturalizar y con vertiginosos atuendos como no nos es hacedero hacernos a ello / serse en conocerse. De su palmaria cortesía con la intercalación destaco este fatigoso párrafo situado en el octavo ensayo:

Ese famoso argumento del consentimiento supuesto unánime de los pueblos, que es el que con un seguro instinto más emplearon los antiguos, no es, en el fondo, y trasladado a la colectividad del individuo, sino la llamada prueba moral, la de Kant, en su Crítica de la razón práctica, empleó, la que se saca de nuestra conciencia-o más bien de nuestro sentimiento de la divinidad-, y que no es una prueba estricta y específicamente racional, sino vital, y que no puede ser aplicada al Dios lógico, al ens summum, al Ser simplísimo y abstractísimo, al primer motor inmóvil e impasible, al Dios Razón, en fin, que ni sufre ni anhela, sino al Dios biótico, al ser complejísimo y concretísimo, al Dios paciente que sufre y anhela en nosotros y con nosotros, al Padre

\footnotetext{
${ }^{1}$ La consecuencia más visible de esta empatía es la ideación de su fábula Vida de de Don Quijote y Sancho.
} 
de Cristo, al que no se puede ir sino por el Hombre, por su Hijo (véase Juan, XIV, 6), y cuya revelación es histórica o, si se quiere, anecdótica, pero no filosófica, no categórica.

En arrojos como este no son incomunes cacofonías que Unamuno no supo advertir (Solo así se comprende lo de que en Dios seamos / Pues lo callan los más de lo que lo sienten). Uno de los riesgos de la generosidad verbal es orillar, cuando no ceder, al remilgo (Hay, sin duda, algo de trágicamente destructivo en el fondo del amor, tal como en su forma primitiva animal se nos presenta, en el invencible instinto que empuja a un macho y una hembra a confundir sus entrañas en un apretón de furia) y a las reiteraciones ( $Y$ de aquí ese sentimiento que observamos con frecuencia y que se ha expresado más de una vez en expresiones satíricas no exentas de irreverencia y acaso de impiedad, de que el cielo de la gloria eterna es una morada de eterno aburrimiento).

Es posible que Unamuno haya percibido estas infelicidades y haya sentido la necesidad de pretextarlas. A fines del capítulo VI declara:

Si en lo que va a seguir os encontráis con apotegmas arbitrarios, con transiciones bruscas, con soluciones de continuidad, con verdaderos saltos mortales del pensamiento, no os llaméis a engaño. Vamos a entrar, si es que queréis acompañarme, en un campo de contradicciones entre el sentimiento y el raciocinio, y teniendo que servirnos del uno y del otro.

No obstante, aun cuando esta advertencia parece remitirse al hemisferio de las ideas, no se oculta que también atinge a la edificación de su prosa, cuyas lástimas no son novedades en ninguno de los apartados de su libro.

Creo que la experiencia de leer a Unamuno no es una recompensa cortés. Podemos atribuir esta indisposición al cansancio que nos suscita su frondosidad sintáctica, pero presumo que hay otro aspecto comprometido. La Tía Tula es una pieza que se encumbra a poco más de 100 páginas cuya historia fue concebida bajo los auspicios de la novela sicológica que Unamuno bautizó como nivola. Al inicio del capítulo XI de la edición crítica de Carlos A. Longhurst (Unamuno, 1996) deparamos con esta singular nota de pie:

Por fin llegamos al estado definitivo de los nombres y del sexo de los hijos de Rosa y Ramiro. La segunda, Tulita, se convierte en Rosita, y el tercero, varón al nacer, 
cambia de sexo para convertirse en Elvira. Sabemos que el mismo Unamuno corrigió las pruebas de la primera edición, por lo cual toda esta confusión no hay más que remedio que achacársela a un lapsus por su parte. (Unamuno, 1996: 125)

No es posible aventurar que Unamuno omitiera la revisión de sus trabajos, pero sí que se abstenía de hacerlo con miramiento. El Unamuno apasionado no es congénere del Unamuno revisor.

Conozco una traducción al portugués de Del sentimiento trágico de la vida de 1996 publicada por Martins. El traductor, Eduardo Brandão, autorizado por el prurito de ser inteligible, ha erosionado la incuria, las cacofonías, los períodos inconclusos y ha reducido la propagación de las frases. Entiendo el objetivo, pero no lo comparto. Creo que un traductor debe ser ante todo un recreador sutil y esmerado de las fortunas pero también de las inopias de un escritor.

Son insistentes las pruebas de que el amoblado estilo de Unamuno dista de ser perspicuo y de que integra aquel cuerpo de escritores que mejora notoriamente con la traducción.

Ensayo sometido a la revista el 22 de abril de 2014.

Ensayo acepto para publicación el 25 de noviembre de 2015. 